\title{
Association Between Mean Fasting Plasma Glucose Level and Survival in Patients with Glioblastoma Multiforme
}

\author{
Mehmet Sercan Erturk $^{1 *}$, Mehmet Celik ${ }^{1}$, Irem Bilgetekin ${ }^{1}$ and Mustafa Karaca ${ }^{2}$ \\ ${ }^{1}$ Department of Endocrinology and Metabolism, Turkey \\ ${ }^{2}$ Department of Medical Oncology, Turkey \\ *Corresponding author: Mehmet Sercan Erturk, Department of Endocrinology and Metabolism, Turkey
}

ARTICLE INFO

Received: 幽 October 09, 2019

Published:

Citation: Mehmet Sercan Erturk, Mehmet Celik, Irem Bilgetekin and Mustafa Karaca. Association Between Mean Fasting Plasma Glucose Level and Survival in Patients with Glioblastoma Multiforme. Biomed J Sci \& Tech Res 22(2)-2019. BJSTR. MS.ID.003719.

Keywords: Glioblastoma multiforme; survival; Glucose; Kanefsky performance score

Abbreviations: Glioblastoma Multiforme; KPS: Karnofsky Performance Score; FPG: Fasting Plasma Glucose; DM: Diabetes Mellitus
ABSTRACT

Objective: High blood glucose levels have been associated with poor outcomes on prognosis in many diseases. This retrospective study evaluated the relationship between plasma glucose level and survival in patients diagnosed with Glioblastoma Multiforme [GBM].

Patients and Methods: The data of 133 Glioblastoma Multiforme [GBM] patients who were followed in the oncology clinic between 2003 and 2016 were evaluated retrospectively. Demographic data, chemotherapy, radiotherapy, blood glucose levels, Karnofsky Performance Score [KPS] and final status of the patients were recorded. Mean fasting plasma glucose level were calculated for each patient. The effects of the available data on survival were evaluated statistically. Patients were evaluated in three groups according to their glucose levels. Patients were evaluated in three groups according to their Fasting Plasma Glucose [FPG] levels. The first group FPG level was less than 100 $\mathrm{mg} / \mathrm{dL}$ [Group 1], the second group FPG level was in the range of 100-126 mg/dL [Group 2] and the third group FPG level was greater than $126 \mathrm{mg} / \mathrm{dL}$ [Group 2]. SPPS 22 was used for statistical analysis. P $<0.05$ was considered as statistically significant.

Results: The mean age of the patients was $53.9 \pm 1.1$ years. Fifty-eight [ $43.6 \%]$ of the patients were female and 75 [56.4\%] were male. Median survival times were 14, 13.5, and 13 months for Group 1, 2 and 3, respectively. The blood FPG level was less than 100 $\mathrm{mg} / \mathrm{dL}$ in 59 patients, the FPG level was between $100-126 \mathrm{mg} / \mathrm{dL}$ in 36 patients and FPG level was higher than $126 \mathrm{mg} / \mathrm{dL}$ in 38 patients. When the patients were evaluated according to FPG levels, the KPS status of the first group was better than the other groups [p: 0.020]. In addition, KPS $[\mathrm{p}<.0001]$ and age $[\mathrm{p}<.0001]$ had a statistically significant effect on survival.

Conclusion: The various FPG levels [Group 1: $<100 \mathrm{mg} / \mathrm{dL}$, Group 2: 100-120mg/dL, Group 3: $>126 \mathrm{mg} / \mathrm{dL}]$ of our study have not demonstrated a significant impact $[\mathrm{p}>0.05]$ on survival in patients diagnosed with GBM. This could be attributed to the importance of the blood sugar control in patients as it can affect KPS indirectly. Future prospective studies with longer follow-up periods are needed to better evaluate the effect of blood glucose level on GBM.

\section{Introduction}

Glioblastoma is the most common malignant primary brain tumor in adults in the $5^{\text {th }}$ and $6^{\text {th }}$ decades. Most patients are treated with a combined approach, including adjuvant postoperative radiation therapy and adjuvant chemotherapy after surgery. Despite treatment, most patients have high recurrence rates and overall survival rates ranging from one to two years [1-4]. Epidemiological studies have suggested that some types of cancer have a higher prevalence and mortality risk in patients with Diabetes Mellitus 
[DM] [5]. Hyperglycemia is defined as the condition of excess circulating glucose concentration. Hyperglycemia indirectly affects cancer cells with an increase in insulin/IGF-1 and cytokine levels in the body. In addition, there are studies in the literature suggesting that hyperglycemia has a direct effect on cancer cell proliferation, apoptosis and metastasis [5-7]. High glucose activates various signaling pathways by adversely affecting cancer cell behavior [8]. The aim of this study was to investigate the relationship between glucose level and survival in patients with GBM.

\section{Patients and Methods}

Table 1: Patient Characteristics According to Fasting Plasma Glucose Levels.

\begin{tabular}{|c|c|c|c|c|}
\hline & Group 1 & Group 2 & Group 3 & \\
\hline Characteristics & (n=59) & $\mathbf{( n = 3 6 )}$ & $\mathbf{( n = 3 8 )}$ & P \\
\hline Dexamethasone dose, mg & & & & 0.456 \\
\hline Median & 0 & 2.5 & 2.5 & \\
\hline $\begin{array}{c}\text { 25\%-75\% percentiles } \\
\text { Karnofsky performance } \\
\text { status }\end{array}$ & $0-4$ & $0-11.5$ & $0-6$ & \\
\hline Median & 90 & 85 & 80 & 0.02 \\
\hline 25\%-75\% percentiles & $80-90$ & $80-90$ & $70-90$ & \\
\hline Age, years & & & & 0.181 \\
\hline Median & 55 & 57.5 & 57 & \\
\hline $25 \%-75 \%$ percentiles & $38-62$ & $47.25-$ & $48.75-$ & \\
\hline Sex & & 62.75 & 64.5 & \\
\hline Male, \% & 67.8 & 44.4 & 50 & \\
\hline Surgery & & & & 0.965 \\
\hline Debulked, \% & 22 & 22.2 & 26.3 & \\
\hline
\end{tabular}

Note: The fasting mean plasma glucose levels for groups 1, 2, and 3 are $<100,100$ to $126,>126 \mathrm{mg} / \mathrm{dL}$, respectively

The data of 133 Glioblastoma Multiforme [GBM] patients who were followed in the oncology clinic between 2003 and 2016 were evaluated retrospectively. Demographic data, chemotherapy, radiotherapy, blood glucose levels, Karnofsky Performance Score [KPS] and final status of the patients were recorded. During the follow-up period mean fasting plasma glucose values were calculated for each patient. The effects of the available data on survival were evaluated statistically. Patients were evaluated in three groups according to their Fasting Plasma Glucose [FPG] levels. The first group FPG level was less than $100 \mathrm{mg} / \mathrm{dL}$, the second group FPG level was in the range of 100-126 mg/dL and the third group FPG level was greater than $126 \mathrm{mg} / \mathrm{dL}$. Since KPS was not normally distributed for age and variances were not homogeneous, Kruskal Wallis was selected for statistical analysis. The Chi-Square [RXC] test was performed for surgical option and gender evaluation in patients, and a table was created according to the Pearson P value. In order to assess the association between the investigated characteristics and overall survival status, multivariate Cox proportional hazard regression analysis was utilized. SPPS 22 was used for statistical analysis. $\mathrm{P}<.05$ was considered statistically significant (Table 1).

\section{Results}

The mean age of the patients was $53.9 \pm 1.1$ years. Fifty-eight [43.6\%] of the patients were female and 75 [56.4\%] were male. The blood fasting plasma glucose level was less than $100 \mathrm{mg} / \mathrm{dL}$ in 59 patients [Group 1], the glucose level was between $100-126 \mathrm{mg} /$ $\mathrm{dL}$ in 36 patients [Group 2] and the glucose level was higher than $126 \mathrm{mg} / \mathrm{dL}$ in 38 patients [Group 3]. Table 1 shows and compares the patient characteristics according to fasting plasma glucose levels of the groups. Investigation of Table 1 revealed that among the investigated characteristics of the groups which are dexamethasone dose, karnofsky performance status [KPS], age, sex, and debulked surgery, only the statistically significant difference was observed at the KPS status [p:0.020].

Median survivals were 14, 13.5, and 13 months for Group 1,2 and 3, respectively. Multivariate Cox proportional hazard regression model was used to investigate the association between the studied characteristics on the overall survival. The results were presented in Table 2. Considering the statistical significance of characteristics presented in Table 2, KPS and age was highly significant $[\mathrm{p}<.0001]$ while the others were insignificant or in other words, had no contribution to overall survival. In particular, there was no observable statistically significant difference between the glucose levels of the groups [ $p>$.05]. Nevertheless, to get a better insight to the screening of the glucose levels in terms of multivariate association between patient characteristics and survival, survival curves comparing the mean fasting plasma glucose levels as a function of time were presented in (Figure 1).

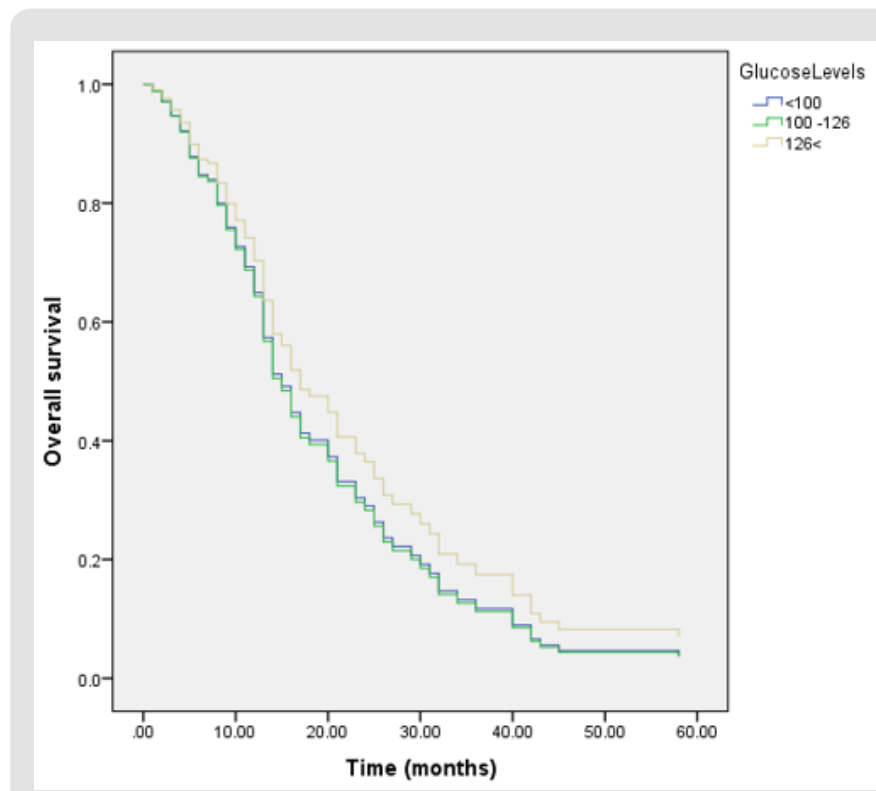

Figure 1: Survival curves comparing groups of mean plasma fasting glucose level. The fasting mean plasma glucose levels for groups 1 to 3 are $<100,100$ to $126,>126$ $\mathrm{mg} / \mathrm{dL}$, respectively. 
Table 2: Patient Characteristics According to Fasting Plasma Glucose Levels.

\begin{tabular}{|c|c|c|c|}
\hline Characteristic & HR & $\mathbf{9 5 \%}$ CI & P \\
\hline Mean Fasting Plasma Glucose & 0.906 & 0.707 to 1.161 & 0.437 \\
\hline KPS & 0.963 & 0.948 to 0.976 & $<.0001$ \\
\hline Age per 10 years & 1.031 & 1.014 to 1.048 & $<0.001$ \\
\hline sex & 1.39 & 0.918 to 2.105 & 0.12 \\
\hline Surgery & 1.242 & 0.961 to 1.603 & 0.097 \\
\hline Dexamethasone dose, mg & 1.009 & 0973 to 1.045 & 0.636 \\
\hline
\end{tabular}

Note: The fasting mean plasma glucose levels for groups one to three are <100, 100 to 126, >126 mg/dL, respectively. Abbreviations: HR, hazard ratio; KPS, Karnofsky performance score.

\section{Discussion}

The most important factors affecting prognosis in GBM patients are age and Karnofsky Performance Status [KPS]. In addition, the level of initial surgical resection is known to affect prognosis. In previously reported studies, the median overall survival of GBM patients is approximately 10 to 12 months [9-11]. In this study, no correlation was found between hyperglycemia and survival time in patients with GBM. Large population-based studies in the literature suggest that diabetes mellitus and impaired glucose tolerance are risk factors for the development of certain types of cancer $[12,13]$. It has been advocated that hyperglycemia frequently causes colon and breast cancers with high mortality and cancer recurrence [14-16]. Poor survival in colon and breast cancer in patients with diabetes, insulin proliferation has been emphasized to increase tumor [17]. High insulin levels have been shown to increase cancer cell proliferation $[18,19]$. In addition, it has been observed that the incidence of breast adenocarcinomas is reduced in tumor-prone transgenic mice treated with metformin, which reduces insulin levels [20]. Rachel L. Derr et al. hyperglycemia was reported to be associated with short survival in 191 GBM patients [21]. In our study, not only KPS has a positive correlation with euglycemia but also it is an important factor for survival. We think that patients have low survival and the effects of hyperglycemia occur mostly in chronic period. Insulin has been shown to stimulate glucose uptake in cultures of human GBM cells [22]. While chronic effects of hyperglycemia can be demonstrated in in vivo studies, we suggest that this effect can be demonstrated more clearly in GBM patients only in long survival periods.

\section{References}

1. Stupp R, Hegi ME, Mason WP, Taphoorn MJ, Janzer RC, et al. (2009) Effects of radiotherapy with concomitant and adjuvant temozolomide versus radiotherapy alone on survival in glioblastoma in a randomised phase III study: 5-year analysis of the EORTC-NCIC trial. Lancet Oncol 10(2): 459.

2. Stupp R, Mason WP, Van Den Bent MJ, Belanger K, Brandes AA, et al. (2005) Radiotherapy plus concomitant and adjuvant temozolomide for glioblastoma. N Engl J Med 352(10): 987.

3. Athanassiou H, Synodinou M, Maragoudakis E, Beroukas K, Karageorgis P, et al. (2005 Randomized phase II study of temozolomide and radiotherapy compared with radiotherapy alone in newly diagnosed glioblastoma multiforme. J Clin Oncol 23(10): 2372.

4. Taphoorn MJ, Stupp R, Coens C, Forsyth P, Bottomley A et al. (2005) Health-related quality of life in patients with glioblastoma: a randomised controlled trial. Lancet Oncol 6(12): 937.

5. Vigneri P, Frasca F, Sciacca L, Pandini G, Vigneri R (2009) Diabetes and cancer. Endocr Relat Cancer. 16: 1103-1123.

6. Suh S, Kim KW (2011) Diabetes and cancer: is diabetes causally related to cancer? Diabetes Metab J. 35(3): 193-198.

7. Johnson JA, Carstensen B, Witte D, Bowker SL, Lipscombe L (2012) Diabetes and Cancer Research Consortium. Diabetes and cancer (1): evaluating the temporal relationship between type 2 diabetes and cancer incidence. Diabetologia 55(3): 1607-1618.

8. Duan W, Shen X, Lei J, Xu Q Yu Y, et al. (2014) Hyperglycemia, a neglected factor during cancer progression. Biomed Res Int pp. 461917.

9. National Comprehensive Cancer Network (NCCN). NCCN Clinical practice guidelines in oncology.

10. Korja M, Raj R, Seppä K, Mäenpää H, Pitkäniemi J, et al (2019) Glioblastoma survival is improving despite increasing incidence rates: a nationwide study between 2000 and 2013 in Finland. Neuro Oncol 21(3): 370 .

11. Ostrom QT, Gittleman H, Xu J, Kruchko C, Barnholtz-Sloan JS, et al. (2016) CBTRUS Statistical Report: Primary Brain and Other Central Nervous System Tumors Diagnosed in the United States in 2009-2013. Neuro Oncol 18: v1-v5.

12. Saydah SH, Loria CM, Eberhardt MS (2003) Abnormal glucose tolerance and the risk of cancerdeath in the united states. Am J Epidemiol 157: $1092-1100$

13. Coughlin SS, Calle EE, Teras LR (2004) Diabetesmellitus as a predictor of cancer mortality in alarge cohort of US adults. Am J Epidemiol 159(3): 1160-1167.

14. Polednak AP (2006) Comorbid diabetes mellitus andrisk of death after diagnosis of colorectal cancer: Apopulation-based study. Cancer Detect Prev 30: 466-472.

15. Yancik R, Wesley MN, Ries LA, Edwards BK, Yates JW, et al. (2001) Effect ofage and comorbidity in postmenopausal breast cancerpatients aged 55 years and older. JAMA 285(7): 885-892.

16. Barone BB, Yeh HC, Snyder CF, Peairs KS, Stein KB, et al. (2008) Long-term all-cause mortality in cancer patients with preexisting diabetesmellitus: a systematic review and meta-analysis. JAMA 300(23): 2754-2764.

17. Gupta K, Krishnaswamy G, Karnad A, Peiris AN (2002) Insulin: a novel factor incarcinogenesis. Am J Med Sci. Mar 323(3): 140-145.

18. Frasca F, Pandini G, Vigneri R (2003) Insulinand hybrid insulin/IGF receptors are major regulatorsof breast cancer cells. Breast Dis 17(1): 73-89.

19. Tran TT, Naigamwalla D, Oprescu AI (2006) Hyperinsulinemia, but not other factors associatedwith insulin resistance, acutely enhances colorectalepithelial proliferation in vivo. Endocrinology 147: 18301837.

20. Anisimov VN, Berstein LM, Egormin PA, Provinciali M, Re F, et al. (2005) Effect of metformin on life span and on the developmentof spontaneous mammary tumors in HER-2/neu transgenic mice. Exp Gerontol 40: 685693.

21. Derr RL, Ye X, Islas MU, Desideri S, Saudek CD, et al. (2009) Association between hyperglycemia and survival in patients with newly diagnosed glioblastoma.J Clin Oncol 27(7): 1082-1086.

22. Rhodes CG, Wise RJ, Gibbs JM (1983) In vivo disturbance of the oxidative metabolism of glucosein human cerebral gliomas. Ann Neurol 14: 614626. 


\section{ISSN: 2574-1241}

DOI: 10.26717/BJSTR.2019.22.003719

Mehmet Sercan Erturk. Biomed J Sci \& Tech Res

(C) This work is licensed under Creative BY Commons Attribution 4.0 License

Submission Link: https://biomedres.us/submit-manuscript.php

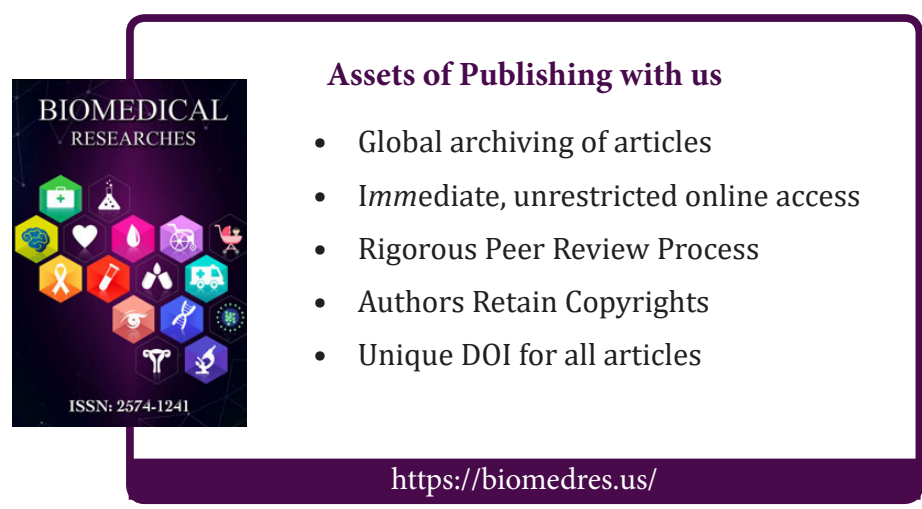

